\title{
A Review on the Production of Lightweight Aggregates Using Industrial Bi-Product and Wastes from Different Sources
}

\author{
Shanko Ayele Abera ${ }^{1}$, Dr. Naresh Kumar ${ }^{2}$ \\ Dilla University, College of Engineering and Technology ${ }^{1}$, \\ Department of Construction Technology and Management, Dilla, Ethiopia \\ Ph.D. Scholar ${ }^{1}$, Associate Professor ${ }^{2} @$ Delhi Technological University ${ }^{1,2}$, \\ Department of Civil Engineering, Delhi, (India) ${ }^{1,2}$
}

\begin{abstract}
The waste materials from industrial are one of the concern issues in sustainable development. Recycle and reduce the waste material is one of the strategies to produce the better sustainable system. One of the methods is by using the waste materials to produce artificial aggregate. There are wide applications of artificial aggregate, for instance construction, agriculture, geotechnical fill, waste water, drainage and many more. Physical properties such as bulk density, specific gravity, unit weight, porosity and water absorption are important criteria. The performance of the artificial aggregate varies, depending on the application.
\end{abstract}

Keywords: waste materials, artificial aggregate, recycling waste materials, key physical properties

\section{Introduction}

Aggregate are materials that have a vast application in several industries. Many industries are dependent on natural resources to gain their aggregate. Thus, the manufacture of lightweight artificial aggregate is developed in order to avoid exhausting of natural resources. Nowadays one of the major issues that needs to be a concern is to minimize and recycling waste materials from industry. The waste materials from industry can be used in producing lightweight aggregate for the construction industry. The lightweight aggregate also has an application on geotechnical fill, insulation products, soil engineering, hydro-culture, drainage, roof gardens and filter [1]. Lightweight aggregate can be produced either from natural rock or manufacture. The typical properties that important for lightweight aggregate are the weight, strength, thermal and acoustical, high fire resistance toughness and depending on the application other properties such as water absorption shrinkage, bonding with cement, elastic properties and abrasion resistance are also considered [2]. There are generally three groups of lightweight aggregate type [2]:

1) Natural lightweight aggregate: natural rock that had been crushed, for instance, pumice, scoria, tuff, breccias, and volcanic cinders.

2) Manufactured structural aggregates: by processing shale, clay, or slate into rotary kilns or sintering machine between $1000^{\circ} \mathrm{C}-1200^{\circ} \mathrm{C}$.

3) Manufactured insulating ultra-lightweight aggregates: by-product lightweight aggregates: a waste material like heavy metal sludge, mining residues, palm shell, paper sludge, pet bottles, sewage sludge, steel slag, bottom ash, fly ash, marine clay.

This paper focuses on the method of producing lightweight artificial aggregate using any by-product and their performance and characterization. The manufactured lightweights from natural source materials that most used and most valued in industry are from shale and expanded clay [2]. However, for any manufactured aggregate or artificial aggregate, the key physical properties are bulk density, specific gravity, unit weight, porosity, and water absorption.

Table 1: Standard to Determine the Properties of Aggregate

\begin{tabular}{|c|c|}
\hline $\begin{array}{c}\text { Properties of Artificial Aggregate } \\
\text { Lightweight Concrete }\end{array}$ & $\begin{array}{c}\text { Specification } \\
\text { and } \\
\text { standard }\end{array}$ \\
\hline Bulk Density and Void in Aggregate & ASTM C 29 \\
\hline Specific Gravity and Absorption & ASTM C127 \\
\hline Sieve Analysis & ASTM C136 \\
\hline $\begin{array}{c}\text { Lightweight Aggregates for Concrete, Mortar } \\
\text { and Grout }\end{array}$ & EN - 13055-1 \\
\hline Lightweight Aggregates for Structural Concrete & ASTM C330 \\
\hline Heat Flow Meter Insulation Test & ASTM C518 \\
\hline Aggregate Impact Value (AIV) & BS 812- \\
& $112: 1990$ \\
\hline Aggregate Abrasion Value (AAV & BS 812- \\
& $113: 1990$ \\
\hline
\end{tabular}

\section{Method of Production Artificial Aggregate}

Basically, production of artificial aggregate is using the same principle which is mixing of raw materials, agglomeration, hardening or binding of the particles and then further processing like curing and sintering. Desire size of artificial aggregate is obtained according to the application by agglomerate any raw waste materials during the production process of artificial aggregate [3]. A process such as sintering, autoclaving and cold bonding are the general 3 methods to produce artificial aggregate after the mixing of raw materials, agglomeration, hardening or binding of the particles. The common method to obtain a lightweight artificial aggregate is through sintering process. There also another researcher such as [4] which has reported on manufacture and performance of cold bonded lightweight aggregate using alkaline activators for high performance concrete. 


\section{International Journal of Science and Research (IJSR) \\ ISSN (Online): 2319-7064}

Index Copernicus Value (2016): 79.57 | Impact Factor (2015): 6.391

\subsection{Sintering}

Previous research had used the sintering method for producing lightweight aggregate in a furnace up until $10000 \mathrm{C}-12000 \mathrm{C}$ to fuse particles at the points of mutual contact [5-9]. The raw materials usually are pelletizing by mixing with $20-30 \%$ water as a binding agent to get the desire and consistency size and dried at 1100C. There are different types ofpalletizer machine that can be used during the agglomeration process by granulation, such as disc or pan type, drum type, cone type and mixer type [10]. The plate revolution speeds during pelletize process using rotating disk are also affecting the physical and mechanical properties of the aggregates. These changes are due to increases coalescence process of the particle up to a limit value [11]. The sintering method required high energy, but has high engineering properties depending on agglomerated material properties and process efficiency [12]. There is also fly ash aggregate that using the 2 steps of thermal treatment where the first at $7500 \mathrm{C}$ for $10-15$ minutes and second the expansion step at $11500 \mathrm{C}-11750 \mathrm{C}$ for $10-15$ minutes [6]. The two-step of high heat treatment gives more porous and property similar to commercial lightweight aggregate compared to one step of heat treatment.

\subsection{Autoclaving}

The autoclaving process is where the chemical such as the cement and lime or gypsum are mixed with the source material in agglomeration stage [13]. After that, the sample area exposed to the autoclaving or cure in pressurized saturated steam at a temperature of $1400 \mathrm{C}$ for several hours.

\subsection{Cold Bonding}

Meanwhile, the cold bonding method is normal water curing at ambient temperature to bonding the mixing material [5]. The bonding achieved from this method are more rigidand higher drying shrinkage. The disadvantages of this method can be overcome by using compaction during agglomeration techniques. The compaction agglomeration technique is by using uni-directional piston type compaction, roll pressing, extrusion and pellet mills. The fly ash class c aggregate in the study [14] shows that increasing the duration of normal water reduce the water absorption and have close properties with autoclave due to dense microstructure formation.

\subsection{Geopolymer}

There also researcher to implement geopolymerisation process bonding during agglomeration by granulation of manufactured aggregates [4,15-18]. Geopolimerisation is an inorganic polycondensation reaction which is yielding threedimensional zeolitic framework to produce geopolymer cement [16]. The hardening mechanism of geopolymeration process is when the aluminium and silicate oxides in any raw material react with alkali polysilicates. The physical and mechanical properties of the geopolymer artificial aggregate are also affected by the molarities and quantity of the alkaline activator use. The geopolymer fly ash shows an increase in strength after exposing to 10000C [20]. The porosity of the artificial aggregate is decreasing after the heat treatment is increasing [15]. The source materials also had a huge role in geopolymer properties according to the reactivity and chemical composition. Lower compressive strength can be seen in cold bond geopolymer artificial aggregate using only fly ash show compared with the geopolymer lightweight aggregate blends with ground granulated blast slag and rice husk ash [4].

\section{Physical Properties of Artificial Aggregate}

\subsection{Specific gravity}

Generally, the different source materials to produce artificial aggregate had a different density and specific gravity. The cold bond metakaolin aggregate size of $20-10 \mathrm{~mm}$ had a specific gravity of 1.83 whereas the cement act as the binder [21]. The specific gravity of cold bonded aggregate of increases when the volume of cement proportion uses to produce the aggregate increase [22]. Other than that, the specific gravity of $100 \%$ ground granulated blast furnace slag cold bonded process aggregate is higher from the fly ash which is 1.97 . The Blaine fineness of fly ash class F also effects on the specific gravity of cold bond artificial aggregate [22]. The saturated surface dry specify gravity of fly ash geopolymer artificial aggregate is 1.89 [18]. Other than that, the lower unit weight of cold bonded geopolymer lightweight aggregate can be obtained by using rice husk ash as source material [4].

The specific gravity of sintered fly ash aggregate is increased from 1.51 to 1.92 when it is exposed higher temperature to $1200 \mathrm{oC}$ from $11000 \mathrm{C}$ [23]. The density of the sintered fly ash aggregate also is increase at a higher temperature from $10750 \mathrm{C}$ to $12000 \mathrm{C}$ [6]. The sintered fly ash aggregates specific gravity or density start to decreasing until the temperature is $10750 \mathrm{C}-11000 \mathrm{C}$ and then increase when exposed to higher temperature because of the close to open porosity of the fly ash aggregate. The specific gravity of sintered sludge ash is decreased as well when the temperature increasing up to $10900 \mathrm{C}$ and start to increase when it exposed to $11000 \mathrm{C}$ [7]. However, the time of the sintered process also affects the specific gravity of the sludge ash aggregates. The specific gravity of sludge ash artificial aggregates is lower when the pellet sintered for 30 minutes than 10 minutes exposed to the same temperature [7].

The composition of the raw material of the sintered artificial aggregates also affects the density. The increasing of the glass content in the aggregate will increase the density [9]. The high calcium content in glass powder act as fluxes which lower the melting point [24]. Thus, the density is increased when it is exposed certain temperature because of the fluxing agent in the aggregate melt and decrease the void of the aggregate. However, the density is decreased as the temperature is very high such as the aggregate is melting and bloating. The sintered artificial aggregate from class F fly ash obtained from different power plants also had different density [25].

\subsection{Water Absorption}

The water absorption capacity of the aggregate is contributed by the open and closed porosity of the artificial aggregates. The addition of lime and cement affect the

\section{Volume 6 Issue 12, December 2017}




\section{International Journal of Science and Research (IJSR) \\ ISSN (Online): 2319-7064}

Index Copernicus Value (2016): 79.57 | Impact Factor (2015): 6.391

physical properties of the fly ash cold bonded aggregates. The water absorption of the fly ash aggregates is decreased by 4-9 \% with addition of lime and cement [12]. The water absorption turns out to be lower if the cement content is increased because of the high rate of the pozzolanic reaction produce calcium silicate hydrate making the structure denser [22]. The addition of ground granulated blast slag also decreases the water absorption of the cold bond geopolymer artificial aggregate [4]. The increase duration of water curing of the cold bonded, steam and autoclaved artificial aggregates shows decreases in water absorption and porosity of the aggregate [14]. In general, the autoclaving aggregates have lower water absorption than steam curing because of the lower porosity. The agglomeration of class F fly ash aggregates through compression method that been sintered shown that the water absorption and porosity are decreased when the soaking timeand temperature are increased from $0.5-2$ hours $10000 \mathrm{C}-11500 \mathrm{C}$ [25]. The porosity and water absorption of fly ash particles reported by [10] are lowest when the specimen is sintered at 9750C-10500C. The maximum value of water absorption is obtained when the artificial aggregate is sintered at $11500 \mathrm{C}$ and then decreased at a higher temperature. The decreasing of the water absorption is due to decrease of open porosity of the surface of the void by less viscous liquid phase. The sintered artificial aggregates reported by [24] show that the water absorption is high when the specific gravity and have low strength due to porosity. The additions of binder also decrease the water absorption as the aggregate becoming denser, discontinuous porosity and small pore size [24].

\subsection{Morphology}

The aggregate morphology can be analyzed by a microscopic study using scanning electron microscope (SEM) analysis.

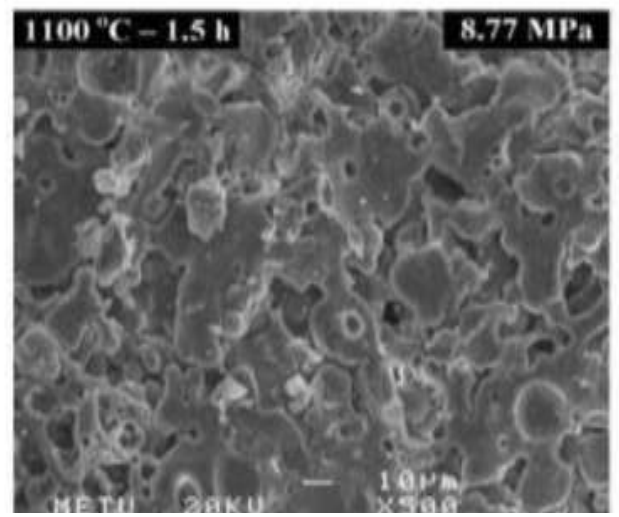

Figure 1(A): The SEM images of fly ash sample for different sintering temperature and soaking time [25].

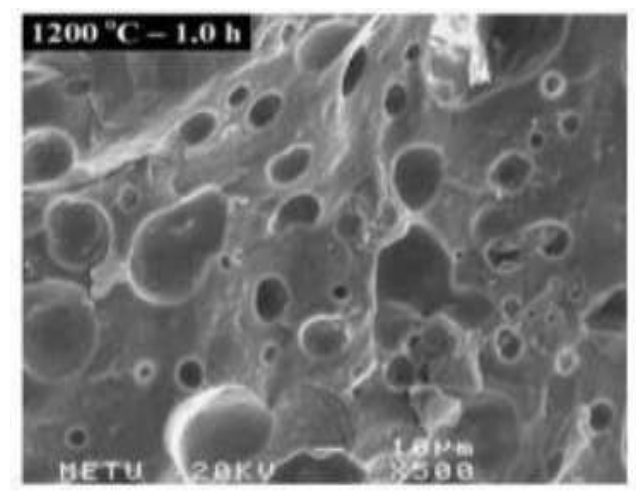

Figure 1 (B): The SEM images of fly ash sample for different sintering temperature and soaking time [25]

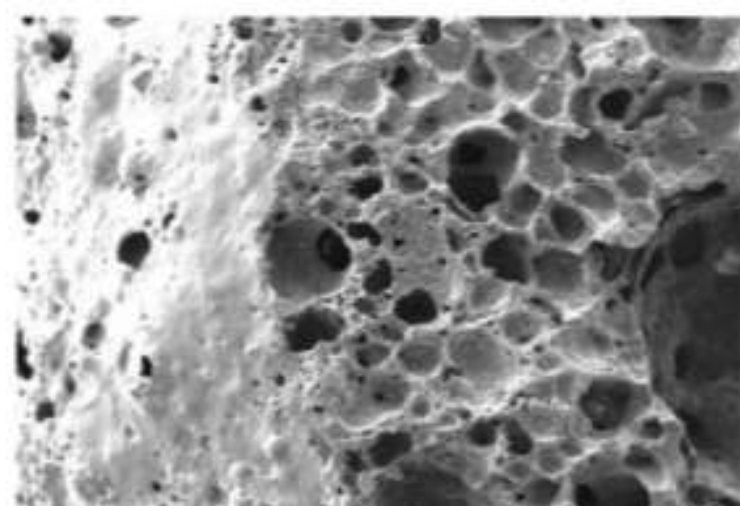

Figure 2: The morphology of the fly ash lightweight aggregate [6].

The porosity and the formation of the binder can be seen by using SEM analysis. The formation of the pore and binder can be analyzed corresponding to the various applications of the manufactured aggregate.

\section{Application and Analysis}

The aggregate has been an important material in various industries as it can be used in may apply depending on their properties. The by-product such as fly ash has been mostly researched to be use for structural concrete. The artificial lightweight aggregate as well can be grouped as a granular thermal insulation product as it has good thermal insulation.

\subsection{Lightweight concrete}

The construction industries are very important as all other industry will need infrastructures in order for development to occur. The important materials in the infrastructures are concrete. The lightweight concrete had been proving more advantages than normal weight in terms of structural loadbearing, as acoustic, thermal insulation and less cost for transportation and building as the dead load from superstructure are decreased [26-28]. There are several ways to produce a light weight concrete. A common method to produce lightweight building materials is by usage of lightweight aggregates [27]. The density of a concrete is reduced because of the air void exist in the lightweight aggregates that replaced the fine aggregate and normal weight course aggregate. Foamed concrete also categorized as lightweight concrete, which is produced by the use of foaming agent to entrap large volume of air into a cement paste or mortar [29]. The concrete performance is affected

\section{Volume 6 Issue 12, December 2017}

\section{www.ijsr.net}

Licensed Under Creative Commons Attribution CC BY 


\section{International Journal of Science and Research (IJSR) \\ ISSN (Online): 2319-7064 \\ Index Copernicus Value (2016): 79.57 | Impact Factor (2015): 6.391}

by several aggregate properties like particle shape and surface texture, relative density, bulk density, the strength of lightweight aggregates, total porosity, grading, moisture content and absorption, modulus of elasticity of lightweight aggregate particles [30]. The aggregate properties affect the performance of the concrete in workability, proportions of mixing, density, and strength.

\subsection{Insulation}

The thermal conductivity coefficient is the basic term for classifying the thermal insulation materials. The unit of the thermal conductivity coefficient is a Kelvin meter per watt $\mathrm{W} / \mathrm{m} \mathrm{K}$ which can be defined as the amount the heat to pass through a certain unit area and thickness in unit time when the temperature difference between two surfaces is 1 Kelvin. The thermal conductivity of a lightweight aggregate concrete is lower than normal concrete by nearly $50 \%$ because of the decrease of the unit weight [31]. The thermal conductivity of normal concrete is in the range of the 0.62 to $3.3 \mathrm{~W} / \mathrm{m} \mathrm{K}$, meanwhile the lightweight concrete is $0.4-1.89$ $\mathrm{W} / \mathrm{m} \mathrm{K}[32]$.

\section{Conclusion}

The industrial waste can be utilised as aggregate as the aggregate has a very large application. The understanding the properties of by the product artificial lightweight aggregate are needed so that the performance can be better than natural aggregate. The use of artificial can provide more sustainable to this world and maybe better performance to traditional system which use the natural aggregate.

\section{References}

[1] C.R. Cheeseman, A. Makinde, S. Bethanis, Resour. Conserv. Recy., 43, 147 (2005).

[2] A.L. Bush, D.P. Bryan, D.R. Hack, Struct. Eng., 88, 14 (2010).

[3] P. Priyadharshini, G.M. Ganesh, S.Sathi, Int. J. Earth Sci. Eng., 05, 540-546 (2012).

[4] C.L.A. Bui, Hwang, C. Chen, K. Lin, M. Hsieh, Constr. Build. Mater., 35, 1056-1062 (2012).

[5] J.M. Bijen, Int. J. Cem. Compos. Light. Concr., 8, 191199 (1986).

[6] M. Aineto, A. Acosta, J.M. Rincon, World of Coal Ash Conference (WOCA) (2005)

[7] J.I. Bhatty, K.J. Reid, Waste water. Res., 7, 363-376 (1989).

[8] C.R. Cheeseman, G.S. Virdi, Resour. Conserv. Recycl., 45, 18-30 (2005).

[9] I. Kourti, C.R. Cheeseman, Resour. Conserv. Recycl., 54, 769-775 (2010).

[10] A. Sivakumar, P. Gomathi, J. Civ. Eng., 3, 42 (2012).

[11]F. Colangelo, R. Cioffi, Materials (Basel), 6, 3139 (2013).

[12] G. Baykal, A. G. Döven, Resour. Conserv. Recycl., 30, 59 (2000).

[13] I. B. Topçu, T. Uygunoglu, Build. Environ., 42, 4108 (2007).

[14] R. Manikandan, K. Ramamurthy, Cem. Concr. Compos., 30, 848 (2008).
[15] A. Abdullah, M. M. A. B. Abdullah, K. Hussin, C.M. Ruzaid, Y. Zarina, M.A.A.M. Salleh, N. Zakaria, M.F.M. Tahie, Key Eng. Mater., 594-595, 151-155 (2013).

[16] R. A Razak, M. Mustafa, A. L Bakri, K. Hussin, K. N. Ismail, Rev. Chim., 7 , 828(2014).

[17]R. Razak, A.M Mustafa Al Bakri, K. Hussin, K.N. Ismail, D. Hardjito, Y. Zarina, Int. J. Mol. Sci., 16, 11629 (2015).

[18] P. Gomathi, A. Sivakumar, Arch. Civ. Eng., 60, (2014).

[19] J. Davidovits, First Int. Conf. Alkaline Cem. Concr., 131 (1994).

[20] M.M.A.B. Abdullah, Fly Ash Porous Material using Geopolymerization Process for High Temperature Exposure. Int. J. Mol. Sci., 13, 4388 (2012).

[21]D.V.B. Desai, A. Sathyam, D. Sireesha, IOSR J. Mech. Civ. Eng., 11, 30 (2014).

[22] M. Gesoglu, E. Güneyisi, H. O. Oz, Mater. Struct., 45, 1535 (2012).

[23] N.U. Kockal, T. Ozturan, J. Hazard. Mater., 179, 954 (2010)

[24] N.U. Kockal, T. Ozturan, Cem. Concr. Compos., 33, 61 (2011).

[25] I. Acar, M.U. Atalay, Fuel, 106, 195-203 (2013).

[26] R. Arellano Aguilar, O. Burciaga Diaz, J. I. Escalante García, Constr. Build. Mater., 24, 1166 (2010).

[27] O. Abdul Kareem, M. Abdullah, K. Hussin, K. Ismail, M. Binhussain, Materials, 6,4450 (2013).

[28] A.R. Rafiza, Adv. Mater. Res., 626, 892-895 (2012).

[29] M.M. Al Bakri Abdullah, et al. Int. J. Mol. Sci., 13, 7186-7198 (2012).

[30] J.P. Ries, et al. Guide for Structural LightweightAggregate Concrete Reported byACI Committee 213 (2010).

[31] S. Akcaozoglu, K. Akcaozoglu, C. D. Atis, Composites Part B, 45, 721-726 (2013).

[32] T.S. Yun, Y.J. Jeong, T. S. Han, K.S. Youm, Energ Buildings 61, 125-132 (2013).

\section{Author Profile}

Mr. Shanko Ayele Abera, originally from Ethiopia. But currently living in Delhi, India. Ph.D. Scholar at Delhi Technological University in Department of Civil Engineering (Geotechnical Engineering).

Dr. Naresh Kumar, Associate Professor at Delhi Technological University in Department of Civil Engineering (Geotechnical Engineering) 